\title{
Relationship Between Violence, Empathy and Aggression
}

\author{
Syeda Nadia Shah ${ }^{1}$ \\ Islamia College Peshawar
}

One of the basic purpose of this study is to determine gender differences and relationship of violence with that of empathy and aggression. The total sample of the study contained sixty-four $(\mathrm{N}=64)$ University students with the age range on 20-25 years. The sample included thirty-two $(n=32)$ male and thirty-two $(n=32)$ female students of University of Peshawar. The results revealed the significant difference on violence between male and female university students males scored significantly higher on violence scale as compared to females. A negligible negative correlation was found between violence and empathy. It was concluded from the finding of the present study that males are more violent than females but there is no significant relation between violence, empathy and aggression.

Keywords. violence, empathy and aggression.

Behavior which is violent in simple words can be described as an individual's intention to show physical aggression against another person or to inflict harm on to others. Violence is a measurable phenomenon, however different people may perceive it differently depending upon the context and circumstances. In order to understand the concept of violence in a better way it is necessary to find and understand the link of perceived aggressor-victim relationship. According to Jan Volavka (1999) people may not identify defensive use of power as violent, even in cases where the amount of power used is intensive than in the original aggression. Studying the relation of violence and aggression with respect to video game has been explored by Montgomery in 2000.

A number of the planned system of force are similar to those thought to be dynamic in contact to society hostility: Expression and strengthening of brutal activities, desensitization to the actual-life circumstances of hostility with greater than before, pro-violence approach, and modification in cognitive processing (World Report on Violence 2002). At the school of Psychology at Birmingham University relations flanked by violence observed from a young age can have a striking outcome on violent youth. Thus adolescents are more susceptible audience to media violence.

${ }^{1}$ Lecturer, Department of Psychology, Islamia College Peshawar 
Violence is thus in a simple way can be defined as use to extensive power or force against self or others in a form of action or words, the term is used as an instrument of manipulation. The situation can be alarming with respect to law and regulations of a specific society, hence it is attempted to be controlled and eliminate. (Merriam-Webster Dictionary, 2009).

Aggression; Harm which has been inflicted on other accidently and without having bad intentions for the victim is not considered as a true aggression as it is not planned. Pain that is a by-product of altruistic behavior or actions is not perceived as an aggression. According to Tedeschi and Felson (1994) the person behind any aggressive act must have intentions and believe that the behavior will harm the target or the victim, and that the target is motivated to avoid the pain or behavior. There are different theories where the concept of aggression has been described by different experts.

Social cognitive theory of Learning; According to this theory humans have a tendency in acquiring the aggressive responses and behaviors exactly the way they acquire other complex behaviors. According to Crick \& Grotpeter (1995) this process take place due to observation or experience. Social learning hypothesis clarify the acquirement of hostile actions, through observational knowledge procedure, and offer a beneficial position of ideas for consideration and explaining the viewpoint and hope that direct societal activities (Cairns \& Cairns, 1989).

Script Theory; This theory stated that when children learn aggressive scripts by viewing violent content in the media. Scripts describe circumstances and direct actions. A young person who has observe quite a few thousand occasion of use a gun to resolve a quarrel on TV is expected to have a very easy to get to draft that has widespread across a lot of circumstances (Bjorkqvist \& Osterman, 1997).

Cognitive Neo Association Theory: This theory stated that the effect of different negative events like that of temperature. Loud noises, provocation, unpleasant odor as well as frustration is the leading cause of aggression (Bushman \& Baumeister, 1998). According to a research study conducted by Coie \& Dodge, (1998) such negative events leads to negative affect which stimulates negativity effects with respect to memory, motor or physiological reactions.

Empathy; The word empathy is described in a variety of ways, and there appear to be more than a few conventions to its study. On the other side, empathy can be defined cognitively with respect to view taking or accepting of others. For example, Hogan in 1969 has defined the term empathy as the ability to intellectually or imaginatively comprehend another's state of mind or condition without actually experiencing that person's feelings". Thus in simple words it is a state of emotional arousal 
to the feelings or experiences of others is empathy. Recently the term has been perceived as a multi-dimensional construct with two major components. One is emotional and the other is cognitive component. (Carstensen \& Pasupathi, 2000).

It is believed that lack of empathy in early childhood is one of the major cause of psychopathology. However empathy itself is positively correlated with moral reasoning, prosocial behavior and low level of aggression. (Preston \& de Waal, 2002).

Males and females be at variance in violent propensity, particularly in the majority aggressive behaviors of assassination and aggravated assault. Laboratory studies often show the same level of gender effects, however less differences with respect to physical aggression. (Parke \& Slaby, 1983).

Empathy and attitudes on the road to violence are significant parts of the procedure of ethical assessment, which may be have an effect on by contact to violence in factual life or in the media. Blunted empathic responding may represent emotional and cognitive desensitization. However cognitive component may play major role in pro violence behavior. (Rule \& Ferguson, 1986). Thus the higher the pro violence attitude the greater will be the aggressive responses. (Lennon \& Eisenberg, 1987).

Female however have found to show low level of pro violent act and high level of empathy then compared to male. Further, researches indicated that one of the reason behind these differences is motivation (Miller \& Eisenberg, 1988). Thus male who are more motivated and interested about the information of guns, violence based television content is one of the contributing factor for aggression and violence. (Elliott, 1993). In a study carried out by Farrell \& Kung (2000) has shown that one of the reason of aggressive behavior is attitude towards violence. Similarly attitude towards an ethnic group that is prejudice, hatred, racism and discrimination has also been found to have a direct or indirect link with that of aggression. Thus negative schema or perception against women is associated with domestic or sexual violence.

Gender differences has been reported not only for aggression but also for empathy and violence as well. Thus women have been reported to be more empathetic and less physically violent then men. This has been confirmed by a study carried out by Radke-Yarrow and Zahn-Waxler in 1994. A research study by Bjorkqvist (1994) has shown that male individuals have a preference towards physical violent behavior, while female are less prone to show violent behavior.

Apart from gender differences, age differences have also been found with respect to violence and empathy. Young adolescents are more prone to be violent and less empathetic then older adults. In addition, societies where people with low level of empathy and elevated exposure 
to society violence are considered to be less stable and more violent than others. (Batson \& Sympson, 1996).

Studies done by Tomada and Schneider (1997) shared similar results. Although in past the concept of aggression was used to be considered as a male phenomenon that female' aggression is not worth the trouble to study. (Henington \& Hughes, 1998). Keeping in view previous studies it has been evaluated that males are found devastatingly hostile in certain kind of crime such as domestic violence, sexual stalking, sexual attack and rape. Females are more often than not the sufferers in these groupings (Pennell et al. 1999).

According to Gault and Sabini (2000). The attitude formation for violence is manipulated by several reasons, specifically violence in observational learning from peers and parents can never be ignored. Therefore attitudes for violence and violent behavior played an important role in the translation of negative affect and cognition of an individual's life.

\section{Objectives}

1. To find out the relationship between violence and empathy.

2. To determine the association between violence and aggression.

3. To investigate the gender differences with respect to violence, empathy and aggression.

\section{Hypotheses}

1. There will be negative relationship between violence and empathy among university students.

2. There will be a positive relationship between aggression and violence among university students.

3. Males will score high on aggression scale as compared to female.

4. Males will score high on violence scale as compared to females.

5. Females will score high on empathy as compared to males.

\section{Sample}

\section{Method}

The sample comprised of sixty-four $(\mathrm{N}=64)$ University students of University of Peshawar, Khyber Pakhtunkhwa, including thirty-two $(n=32)$ males and thirty-two $(n=32)$ females, ranging in age between 20 to 25 years. Purposive sampling technique was used.

\section{Instruments}

\section{Toronto Empathy Questionnaire}

The TEQ is a brief, reliable, and valid instrument (Cronbach's $\alpha$

$=.85$ ) for the assessment of empathy. It consisted of 16 items and contains 
an equal number of positively and negatively worded/scored items Responses were given using a 5-point Likert-scale corresponding to various levels of frequency i.e., never, rarely, sometimes, often, always (R. Nathan Spreng \& Margaret C. McKinnon et al. 2009)

\section{Revised Attitude Towards Violence Scale}

In the following study the revised version of velicer attitudes toward violence scale (VATVS) has been used for the individuals' evaluations of violence in general it consists of 39 items with chronbach alpha .92. That appears to measure four attitudinal constructs for men and women: violence in war (war $\alpha=.79)$, penal code violence $(\alpha=.83$ ) corporal punishment of children $(\alpha=.87)$ and intimate violence $(\alpha=.89)$ (Anderson, Benjamin, Wood, \&Bonacci, 2006).

\section{Buss and Perry Aggression Scale}

The Buss and Perry aggression scale was used in this study for the measurement of aggression. This scale represents revisions of a Buss and Durkee hostility inventory. Its 29 items 5 points scale from 1 (extremely uncharacteristic of me)to 5 extremely uncharacteristic of me. It consists of four subscale i.e physical aggression, verbal aggression, hostility and anger. Internal consistency for four subscales and total score range from .72 (verbal aggression) to .89 (total BPAQ score) (Buss and Perry, 1992).

\section{Procedure}

After obtaining the permission from the respective institutional authorities and of the participants the three questionnaires (Buss \&Perry 1992, Toronto empathy scale R. Nathan Spreng \&, Margaret C. McKinnon et al. 2009 and RAVS Anderson et al. 2006) has been administered individually on university students of different departments in university of Peshawar. Sample comprised of 60 subjects $(\mathrm{N}=60)$ including 32 males and 32 females. The subjects were assured about the confidentiality of the given information. They were briefly described about the purpose of the study. After providing with the scales subjects were thus requested to answer to all the questions honestly. So that reliable results could be obtained. The information thus obtained from all subjects were analyzed statistically after the data has been collected.

Table 1

\section{Results}

Alpha Reliability Coefficient of the Major Scales of the Study

\begin{tabular}{lcc}
\hline Scale & No of Item & Alpha Reliability \\
\hline Buss and Perry questionnaire & 29 & .75 \\
Attitude Towards Violence Scale. & 39 & .84 \\
Toronto Empathy Scale & 16 & .57 \\
\hline
\end{tabular}

Peshawar Journal of Psychology and Behavioral Sciences, 2015, Vol. 1, No. 1, 73-84 
Table 1 shows alpha reliability coefficient of the major scales of the study. Buss Perry Questionnaire and Attitude towards Violence scale has high reliability where as Toronto empathy scale has relative moderate reliability on the data of the present study.

Table 2

Frequencies of Respondents According to the Age and Gender $(\mathrm{N}=64)$

\begin{tabular}{cccccc}
\hline Age ranges & \multicolumn{2}{c}{ Male } & & \multicolumn{2}{c}{ Females } \\
\cline { 2 - 3 } \cline { 5 - 6 } & $\mathrm{F}$ & Percent & & $\mathrm{F}$ & Percent \\
\hline $18-21$ & 10 & 31.3 & & 05 & 15.6 \\
$22-25$ & 22 & 68.7 & & 27 & 84.3 \\
Total & 32 & 100 & & 32 & 100 \\
\hline
\end{tabular}

Table 2 shows frequency distribution of the sample on the basis of age and gender.

Table 3

Mean, Standard Deviation and t-test on Scores of Empathy Scale between Male and Female Students

\begin{tabular}{|c|c|c|c|c|c|c|c|c|}
\hline \multicolumn{2}{|c|}{$\begin{array}{l}\text { Females } \\
(\mathrm{n}=32)\end{array}$} & \multicolumn{4}{|c|}{$\begin{array}{l}\text { Males } \\
(\mathrm{n}=32)\end{array}$} & 95 & ${ }_{0} \mathrm{CI}$ & \multirow{2}{*}{$\begin{array}{l}\text { Cohen' } \\
\frac{\mathrm{s}}{\mathrm{d}}\end{array}$} \\
\hline $\mathrm{M}$ & SD & $\mathrm{M}$ & SD & $\mathrm{t}(62)$ & $p$ & LL & UL & \\
\hline 34.6 & 8.6 & 32.0 & 5.4 & 1.44 & .15 & -0.98 & 6.18 & 0.36 \\
\hline
\end{tabular}

Table 3 shows results are non-significance but the mean differences shows that females have high level of empathy as compared to males, which is consistent with our hypothesis.

Table 4

Mean, Standard Deviation and t-test on Scores of Violence Scale between Male and Female Students

\begin{tabular}{llllllllc}
\hline $\begin{array}{l}\text { Females } \\
(\mathrm{n}=32)\end{array}$ & \multicolumn{2}{l}{$\begin{array}{l}\text { Males } \\
(\mathrm{n}=32)\end{array}$} & & & & \multicolumn{2}{c}{$95 \% \mathrm{CI}$} & Cohen's \\
\hline $\mathrm{M}$ & $\mathrm{SD}$ & $\mathrm{M}$ & $\mathrm{SD}$ & $\mathrm{t}(62)$ & $\mathrm{P}$ & LL & $\mathrm{UL}$ & $\mathrm{d}$ \\
\hline 125.0 & 23.9 & 146.9 & 24.23 & -3.634 & .001 & -33.94 & -9.85 & 0.91 \\
\hline
\end{tabular}

Table 4 shows results are significant but the mean differences also shows that females have low level of violence as compared to males which is consistent with our hypothesis 
Table 5

Mean, Standard deviation and t-test Between Males and Females of Scores of Aggression Scale $(\mathrm{N}=64)$

\begin{tabular}{ccccccccc}
\hline $\begin{array}{l}\text { Females } \\
(\mathrm{n}=32)\end{array}$ & \multicolumn{2}{l}{$\begin{array}{l}\text { Males } \\
(\mathrm{n}=32)\end{array}$} & & & \multicolumn{2}{c}{ 95 \% CI } & Cohen's \\
\hline $\mathrm{M}$ & $\mathrm{SD}$ & $\mathrm{M}$ & $\mathrm{SD}$ & $\mathrm{t}(62)$ & $\mathrm{P}$ & $\mathrm{LL}$ & $\mathrm{UL}$ & $\mathrm{D}$ \\
\hline 81.2 & 15.7 & 87.5 & 12.2 & -1.79 & .07 & -13.32 & 0.72 & 0.44 \\
\hline
\end{tabular}

Table 5 the results are non-significant but the mean differences shows that males have high level of aggression as compared to females which is consistent with our hypothesis.

Table 6

Correlation of Empathy and Violence among Males and Females $(\mathrm{N}=64)$ Scale Attitude towards violence Scale

\begin{tabular}{ll}
\hline Toronto empathy scale & -.14 \\
\hline
\end{tabular}

Table 6 shows that there is negative correlation between empathy and violence $(\mathrm{P} \geq .05)$, but the correlation is not significant.

Table 7

Correlation of Aggression and Violence Among Males and Females $(\mathrm{N}=64)$

\begin{tabular}{lc}
\hline Scale & Attitude towards violence Scale \\
\hline Buss and Perry Aggression Scale & -.13 \\
\hline
\end{tabular}

Table 7 shows that there is negative correlation between aggression and violence $(\mathrm{P} \geq .05)$ but the correlation is not significant

\section{Discussion}

The basic purpose of the present study was to evaluate the relationship between violence, empathy and aggression among university students. This study also intended to explore the relationship among violence, empathy and aggression with respect to gender differences. The detailed of the present study is given below:

In table 3 alpha coefficient of attitude towards violence scale and empathy scale has also find out. Thus the alpha value for ATV scale is find out to be .84 while for Toronto empathy scale its .57 the first step of this study, we find out the alpha coefficient of the Buss and Perry 
questionnaire, which was .75(see Table 1). This value indicated that the scale is internally consistent.

In table 4 the frequency with respect to age and gender has been find out. As one of the purpose of the study is to examine the gender differences in levels of violence, aggression and empathy thus Table 5 shows the result for gender differences with respect to empathy. According to the study of Toussaint and Webb (2007) girls are found to be more empathetic as compared to boys. A similar study conducted by Macaskill et al. (2002) based on gender differences with respect forgiveness and empathy also showed that females were higher then males in level of empathy and so as forgiveness. In table 4 the results are non-significance $(p \leq .05)$ but the mean differences shows that females have high level of empathy as compared to males, which is consistent with our first hypothesis. Though the results obtained were non-significant that may be due to the small sample size.

Studies have constantly shown elevated rates of aggression for males than for females, and particularly increased rates of violence. One of the reasons females have lower rates of offending is because they acquire social cognitive skills earlier in life than males do and because they have better pro-social skill (Sarah Bennet et al 2004). Analysis of the present study has also shown the same result, in table 6 the results are found significant $(\mathrm{p} \leq .05)$, the mean differences also shows that females have low level of violence as compared to males which is consistent with our second hypothesis. Though the results obtained were non-significant that may be due to the small sample size.

Studies that have been done in past many years have shown high difference among male and females regarding the level of aggression. Early on studies on gender differences in aggression appear to show that men were devastatingly more aggressive than women, a view that was confronted when social psychologists started to study non-overt types of aggression (e.g., Lagerspetz, Bjorkqvist, \& Peltonen, 1998). Afterwards research studies have concluded remarkable gender distinction in aggression forms, at least in children and adolescents. Boys usually employ in aggression that entails a direct physical and/or verbal physical attack (ie hitting and yelling), while girls use fewer overt types of aggression such as negative conversation. (Owens et al. 2000)

The results in table 7 are non although non-significant $(\mathrm{p} \leq .05)$, but the mean differences shows that males have high level of aggression as compared to females which is consistent with our third hypothesis.

A number of studies have shown the relationship between empathy, violence and aggression. Negative correlation between violence and empathy can be proved through various past studies. Relationships between lower empathy and social maladjustment and violence in youth have also been found (Cohen \& Strayer, 1996). The study of Deanna and 
Trustcot (2004) have shown that Adolescents who report high levels of exposure to violence will report low levels of empathy and frequent use of violence. The results in table 8 shows the correlation between empathy and violence, though there is no significance found but the mean difference obtained support our fourth hypothesis.

Violence whether in real life situation, or in media always cause devastating effects on behavior of human beings. Different studies have shown the positive correlation between aggression and violence. Attitudes toward violence play an important role in a wide variety of aggressive behaviors. For example, negative attitudes toward specific racial or ethnic groups (i.e., discrimination) are associated with heightened aggression against those groups (Rogers, 1983). Table 9 shows the correlation between violence and aggression, although the result obtained are of no high significance but the mean differences obtained showed the negative correlation between violence and aggression. These findings are in correspondence with our fifth hypothesis.

\section{Conclusion}

It is concluded from the findings of the current study that there are obvious gender differences on aggression, violence and empathy. Thus females who are less prone to show physical aggression are more likely to be empathetic and less violent in different social situations. Findings of the past studies indicated that there is a positive correlation between aggression and violence and negative correlation between empathy and violence, however non-significant correlation has been found in this study. It has also been concluded from this research that violence and aggression can affect an individual's level of empathy. Thus a person with high level of empathy are less vulnerable to develop positive attitude towards violence and show aggression.

\section{Limitation and Recommendations}

The study has following limitation and suggestions.

1. Small sample size and convenient sampling technique has limited the significance of the findings .Thus its generalizability has also been reduced.

2. Large sample size of different age groups should be taken from different regions to increase the generalization of findings to general population.

3. More detailed studies on role of empathy in positive and negative behaviors both would help in better understanding of the level of effect of empathy in violence and aggression. Positive may include sample of the students who are more calm and nonaggressive comparing with aggressive population in association with empathy. 
4. Sampling techniques needs to be improved and more objective oriented, as in the present study sample was randomly selected students of the university. It will be really helpful if aggressive and violent students could be selected through proper screening prior to the main study data collection, for drawing accurate conclusions of the findings of the study.

\section{References}

Anderson, C. A., Benjamin, A. J., Jr., Wood, P. K., \&Bonacci, A. M. (2006). Development and testing of the Attitudes Toward Violence Scale: Evidence for a four-factor model. Aggressive Behavior,32, 122-136.

Batson CD, Sympson SC, Hindman JL, Decruz P, Todd RM, Weeks JL, et al.(1996) I've been there, too": Effect on empathy of prior experience with a need. Personality and Social Psychology Bulletin 22:474- 482 .

Bennet.S et al (2004) Explaining gender differences in crime and violence: The importance of social cognitive skills. 10(3), 263-288

Bjorkqvist K.(1994) Sex differences in physical, verbal, and indirect aggression: A review of recent research. Sex Roles 30:177-188.

Bushman BJ, Baumeister RF. (1998). Threatened egotism, narcissism, self-esteem, and direct and displaced aggression: Does self-love or self-hate lead to violence? J. Pers. Soc. Psychol.75:219-29.

Buss, A. H., \& Perry, M. P. (1992). The aggression questionnaire. Journal of Personality and Social Psychology, 63, 452-459.

Cairns RB, Cairns BD, Neckerman HJ, Ferguson LL, GariépyJ.(1989) Growth and aggression: Childhood to early adolescence. Developmental Psychology ;25:320-330.

Carstensen LL, Pasupathi M, Mayr U, Nesselroade JR. (2000) Emotional experience in everyday life across the adult lifespan. Journal of Personality and Social Psychology 79:644-655.

Cohen, D., \& Strayer, J. (1996). Empathy in conduct-disordered and comparison youth. Developmental Psychology, 32,988-998.

Coie, JD.; Dodge, KA.(1998 )Aggression and antisocial behavior. In: Eisenberg, N., editor. Handbook of child psychology. New York: Wiley, 779-862.

Crick NR, Grotpeter JK. (1995)Relational aggression, gender, and socialpsychological adjustment. Child Development,66:710-722. .

Elliott DS.(1994) Serious violent offenders: Onset, developmental course and termination--the American Society of Criminology 1993 Presidential Address. Criminology 32(1):1-21.

Farrell AD, Kung EM, White KS, Valois RF.(2000) The structure of selfreported aggression, drug use, and delinquent behaviors during early adolescence. Journal of Clinical Child Psychology 29:282- 292. 
Gault BA, Sabini J. (2000)The roles of empathy, anger, and gender in predicting attitudes toward punitive, reparative, and preventative public policies. Cognition and Emotion 14:495-520.

Henington C, Hughes JN, Cavell TA, Thompson B.(1998) The role of relational aggression in identifying aggressive boys and girls. Journal of School Psychology ;36:457-477.

Hogan, R. (1969). Development of an empathy scale. Journal of Consulting and Clinical Psychology, 33, 307-316.

Jan Volavka.(1999).The Neurobiology of Violence, An Update, Journal of Neuropsychiatry ClinNeurosci 11:3

Lagerspetz, K., Bjorkqvist, K., \& Peltonen, T. (1988). Is indirect aggression typical of females? Gender differences in aggressiveness in 11- to 12-year-old children. Aggressive Behavior, 14, 403-414.

Lennon, R.; Eisenberg, N. (1987) Gender and age differences in empathy and sympathy. In: Eisenberg, N.;Strayer, J., editors. Empathy and its development. Cambridge, UK: Cambridge University Press; 195217.

Merriam-webster.com, Merriam-Webster Dictionary Retrieved January 8, 2009.

Miller PA, Eisenberg N. (1988) The relation of empathy to aggressive and externalizing antisocial-behavior. Psychological Bulletin 103:324344.

Montgomery, K. (2000). Youth and digital media: A policy research agenda. Journal of Adolescent Health, 27S, 61-68.

Owens, L., Shute, R., \& Slee, P. (2000). "Guess what I just heard"!Q: Indirect aggression among teenage girls in Australia. Aggressive Behavior, 26, 67-83.

Parke, RD.; Slaby, RG.(1983) The development of aggression. In: Hetherington, EM., editor. Handbook of child psychology. New York: Wiley;. 547-641.

Pennell, Amanda. Browne, Kevin (1999) 'Film violence and Young offenders' Aggression and Violent behavior, pp 13-38.

Preston SD, de Waal FBM. (2002) Empathy: Its ultimate and proximate bases. Behavioral and Brain Sciences 25:1-72.

Radke-Yarrow M, Zahn-Waxler C, Richardson DT, Susman A.(1994) Caring behavior in children of clinically depressed and well mothers. Child Development 65:1405-1414.

Rogers RW. 1983. Race variables in aggression. In GeenR,Donnerstein E (eds): 'Aggression: Theoretical and Empirical Reviews,' Vol. 2. New York: Academic Press, pp 27-50.

Rule, B. K., \& Ferguson, T. J. (1986).The effects of media violence on attitudes, emotions, and cognitions. Journal of Social Issues, 42, 29 50 . 
Spreng, R. Nathan, McKinnon, Margaret C., Mar, Raymond A., and Levine, Brian (2009). The Toronto Empathy Questionnaire: Scale development and initial validation of a factor-analytic solution to multiple empathy measures. Journal of Personality Assessment, 9 (1), 62-71.

Tedeschi JT, Felson RB. (1994). Violence, Aggression,\& Coercive Actions. Washington, DC: American Psychological Association.

Tomada G, Schneider BH.(1997) Relational aggression, gender, and peer acceptance: Invariance across culture, stability over time, and concordance among informants. Developmental Psychology; 33:601 